\title{
SPLENIC ENLARGEMENT IN CONGESTIVE HEART FAILURE AND ACTIVE RHEUMATIC INFECTION
}

\author{
BY \\ MAHOMED IBRAHIM, A. SOROUR, AND A. ELSHERIF \\ From the Medical Unit, Fouad Fust University, Cairo \\ Received October 10, 1949
}

It is generally stated that the spleen rarely if ever enlarges sufficiently to become palpable in uncomplicated congestive heart failure. Rolleston (1908) and Held (1919) both concluded that a palpable spleen in congestive failure was due to some complication. Talley and Lindsey (1924) in 198 cases of congestive failure in adults found 3 with palpable spleens. Fishberg (1940) in discussing the question concludes that the spleen may enlarge at the onset of failure, but that, later, it decreases in size owing to fibrosis and to contraction, which contributes to increasing the circulating blood volume, so that in chronic failure a condition of "cyanotic atrophy" of the spleen is found. Fishberg mentions the following causes of a palpable spleen in heart failure:-

(1) Active infection, e.g. rheumatic carditis.

(2) Cardiac cirrhosis of the liver from chronic right-sided heart failure.

(3) Mediastino-pericarditis.

(4) Large left pleural effusion displacing the spleen downwards.

Similar views have been expressed by Boyd (1940) and Ravenna (1943). Fowler (1947) from a study of the pathological records at the Peter Bent Brigham Hospital, Boston, concluded that 12 out of 97 cases of uncomplicated congestive failure had spleens large enough to be palpable, assuming that a weight of $300 \mathrm{~g}$. or more would render the spleen palpable as suggested by Barron and Litman (1932). In only one of these twelve cases was the spleen actually recorded as being clinically palpable, and this discrepancy was attributed to special difficulty in palpation of the spleen in cardiac cases - for example - ascites, œdema of the abdominal wall, and lack of co-operation on the part of the patient. In failure due to rheumatic valvular disease, the spleen was always large enough to be palpable, and cardiac hepatic cirrhosis was common. Wahi and Mathur (1949) found, in 690 cases of congestive failure studied in India, 7 per cent with palpable spleens. They also noticed from pathological observation that a spleen weighing $300 \mathrm{~g}$. or more was often found although it had not been palpated clinically.

\section{Present Investigation}

During the last two years, the occurrence of clinical splenic enlargement has been investigated in 206 cases of congestive heart failure and in 67 cases of active rheumatic carditis without failure. The selection of cases was difficult on account of the frequency of splenic enlargement in Egypt from bilharziasis and malaria, but as far as possible all such cases, including doubtful ones, were excluded. Cases with bacterial endocarditis were also excluded.

The cases studied were grouped as follows:-

I (a) Congestive failure due to rheumatic heart disease-111 cases.

(b) With active rheumatic infection-14 cases.

(c) Without active infection-97 cases.

II Congestive failure of non-rheumatic ætiology-95 cases.

III Active rheumatic infection without congestive failure- 67 cases. 
In these 273 cases, a palpable spleen was found in 7 in which no other cause than failure or active rheumatic infection existed. Of these 7 cases of splenomegaly, 3 had failure and active rheumatic infection; 2 had failure due to chronic rheumatic heart disease, and 2 had active rheumatic infection without failure. No case of enlarged spleen occurred in the group of 95 cases of failure of nonrheumatic ætiology.

\section{SUMMARY OF CASES}

I (a) Congestive failure with active rheumatic infection.

Case 1. Male, aged 17, had recurrent rheumatic infection with failure. Heart enlarged with signs of mitral stenosis and congestion of predominantly hepatic type with little odema. Liver enlarged five fingers below costal margin in mid-clavicular line, and pulsating. Right hydrothorax. Fever, joint pains, rheumatic nodules and raised E.S.R. The spleen was sometimes palpable at the costal margin, sometimes impalpable.

Case 2. Male, aged 14, with cardiac symptoms of two years' duration. Signs of old mitral disease with an acute exacerbation of rheumatic carditis, and congestion of hepatic type. The spleen was palpable three fingers below the costal margin, soft and tender. Fatal termination; no necropsy obtained.

Case 3. Female, aged 30, with chronic mitral disease. Admitted to hospital with acute rheumatic fever and active carditis, with slight congestion of neck veins and liver. Dry pericarditis, right pleural effusion, and consolidation at the left base developed, venous engorgement increased, and œdema appeared. The spleen, not palpable on admission, was felt three fingers below the costal margin, soft and tender. Bilateral pleural effusions needed paracentesis, and joint pains with irregular fever persisted. With subsidence of active infection and failure, first the spleen, then the liver diminished in size, and two months after admission, when failure had subsided, the spleen was no longer palpable.

I (b) Congestive failure due to rheumatic heart disease without active infection.

Case 4. Male, aged 19, with history of urinary bilharziasis 8 years previously, and of cardiac symptoms of two years' duration. Heart enlarged with signs of mitral stenosis and congestive failure with tricuspid regurgitation, but no oedema. Liver pulsating and enlarged three fingers below costal margin, firm and tender. Spleen palpable three fingers below costal margin, firm but not tender. As the dregree of congestion waxed and waned, the size of the spleen varied accordingly. Two months later, when quite free from failure, the liver enlargement persisted, and the spleen was just palpable in the right lateral position.

Case 5. Male, aged 17, with history of urinary bilharziasis 7 years previously. Signs of mitral disease with aortic regurgitation, and congestive failure. Liver enlarged and pulsating, five fingers below costal margin, and tender. A palpable rub over liver due to perhepatitis developed. As the patient improved slightly, the spleen became smaller and less tender, remaining just palpable, but the liver was unchanged.

Case 6. Male, aged 15, with history of periodic fever, arthritis, sore throat, epistaxis, and chorea during the last 3 years. Rheumatic nodules, raised E.S.R., and slight fever. Signs of mitral stenosis without heart failure. Spleen enlarged one finger below costal margin, soft and tender.

Case 7. Female, aged 25 , admitted to hospital with subacute rheumatic polyarthritis, rheumatic nodules, and raised E.S.R. During 6 weeks in hospital, the spleen was palpable one finger below costal margin, soft and tender, and the arthritis lingered.

\section{Discussion}

It is evident that palpable splenic enlargement is rare in congestive heart failure, for it occurred in only 5 of our 206 cases, and no instance of it occurred in cases of failure of non-rheumatic ætiology. When splenomegaly does occur, there is some special cause, and the following factors appeared to favour it:-

(1) congestive failure with predominantly hepatic congestion,

(2) associated liver cirrhosis, and

(3) active rheumatic infection.

In the rheumatic group, splenic enlargement occurred in cases of mitral stenosis with congestion of predominantly hepatic type, though not all such cases presented splenomegaly. In 3 cases of this type, 2 were associated with active rheumatic infection, and 1 with liver cirrhosis. Cases 4 and 5 had an associated liver cirrhosis, probably of bilharzial origin, and one of these had perihepatitis; in both liver enlargement persisted after failure had subsided. It may be assumed that liver cirrhosis increases the splenic congestion due to heart failure. 
Active rheumatic infection by itself rarely accounts for a palpable spleen ( 3 per cent of our cases), but when associated with heart failure splenomegaly is more frequent (20 per cent of our cases). In 3 cases with splenomegaly and active rheumatic infection, rheumatic nodules were present, indicating a severe infection.

The size of the spleen varied from being just palpable to three fingers below the costal margin. It was usually soft and tender except in two cases with liver cirrhosis In 3 cases the size of the spleen fluctuated with the degree of failure and rheumatic activity.

\section{SUMMARY}

Previous reports relating to palpable splenomegaly in congestive heart failure and active rheumatic infection are reviewed.

A series of 206 cases of congestive heart failure and 67 cases of active rheumatic infection without failure has been investigated in regard to the occurrence of palpable splenic enlargement. This occurred in 7 cases; 5 with congestive failure and 2 with active rheumatic infection without failure.

The factors responsible for splenic enlargement are discussed.

\section{REFERENCES}

Barker, L. F. (1930). Med. Clin. North Am., 14, 215.

Barron, M., and Litman, A. B. (1932). Arch. intern. Med., 1, 240.

Boyd, W. A. (1940). The Pathology of Internal Disease, 3rd ed., London.

Fishberg, A. M. (1940). Heart Failure, 2nd ed., London.

Fowler, N. O. (1947). Ann. intern. Med., 31, 733.

Held, I. W. (1919). Med. Clin. North Am., 3, 519.

Ravenna, P. (1943). Arch. intern. Med., 72, 786.

Rolleston, H. D. (1908). Brit. med. J., 2, 1157.

Talley, J. E., and Lindsey, W. H. (1924). J. Amer. med. Ass., 83, 423.

Wahi, P. N., and Mathur, K. S. (1949). Indian Heart J., 1, 230. 